\title{
Anaphoric Demonstratives and Their Antecedents in English Academic Discourse
}

\author{
Cunying Fan ${ }^{1,2}$ \\ ${ }^{1}$ Department of English Language \& Literature, Gyeongsang National University, Gyeongnam, South Korea \\ ${ }^{2}$ Foreign Languages Teaching \& Research Department, Qufu Normal University, Shandong, China \\ Correspondence: Cunying Fan, Department of English Language \& Literature, Gyeongsang National University, \\ South Korea. Tel: 82-10-6899-8058. E-mail: fan8058@126.com
}

Received: September 27, 2013 Accepted: November 8, 2013 Online Published: November 24, 2013

doi:10.5539/ijel.v3n6p73

URL: http://dx.doi.org/10.5539/ijel.v3n6p73

\begin{abstract}
This paper investigates the distribution and specific properties of anaphoric demonstratives with directly recoverable antecedents in English academic discourse. By analyzing 359 tokens of demonstrative reference of this, that and it with directly recoverable antecedents from the academic section of the online corpus COCA, the paper finds that the general frequency of demonstratives in English academic discourse is that this is more frequent than it and then it is more frequent than that. The main reason underlying this order is due to the different functions of this, that and it to mark topics. These functions correlate with features or purposes of academic discourse. About the types of antecedents, the paper finds that most common antecedents of this are non-nominal and most common antecedents of $i t$ and that are nominal. What's more, three different semantic relations between demonstratives and their antecedents are recognized in this paper: direct coreference, indirect coreference and labeling or rephrasing relations. The paper suggests that the underlying motivation for the interaction between anaphoric demonstratives and their antecedents is the writer's perception of events in temporal order.
\end{abstract}

Keywords: anaphoric demonstratives, recoverable antecedents, English academic discourse

\section{Introduction and Literature Review}

Since Lakoff (1974) treated English demonstratives such as this and that under three categories: spatio-temporal, discourse and emotional deixis, the discourse functions of this and that have attracted many linguists' attention. Two main approaches to study demonstratives are the proximity approach and the focus approach.

The proximity approach suggests that the choice of demonstratives this and that relies primarily on relative distance from the speaker. The choice of this and that centers around the speaker as the primary locus of referential information, with this typically denoting some entity that is "near the speaker" and that an entity that is "far from the speaker" or "remote" (Fillmore, 1997; Halliday \& Hasan, 1976; Huddleston, 1984; Kaplan, 1989; Levinson, 1983; Quirk et al., 1985; Ramsey, 1968; etc.). However, the proximity approach is "a static model governing the choice of one demonstrative over the other" (Strauss, 1993, p. 403) and "exactly how the spatial proximity/nonproximity distinction should be extended to account for all the various uses of this and that has not been made fully explicit yet" (Lakoff, 1974, p. 355).

Recognizing these problems, some researchers try to find an alternative account - the focus approach for the phenomenon of demonstratives. In the focus approach, focus is the most critical factor in the speaker/writer's choice of demonstratives (Kirsner, 1979; Linde, 1979; Sidner, 1983; Strauss, 1993). Drawing on Kirsner's theory of High vs. Low Deixis, Strauss (1993) sets up a focus frame work on the notion of degree of referential focus as being the primary motivating factor behind the choice of demonstratives, with this signaling High focus, that Mid focus and $i t$ referentially Low focus (Strauss, 1993). Though this focus approach is more interactive and it takes into account communicative factors, including the hearer, the relationship between interlocutors, it does not give a specific criterion to classify the degree of focuses.

The proximity and focus approach can explain some usages of demonstratives, but these two accounts have "paid too much attention to the use or function in discourse and made little of a variety of forms in demonstratives" (Kim, 2006, p. 189) and they ignore the relationship between demonstratives and their 
antecedents in discourse. Considering this, $\operatorname{Kim}(2000,2006)$ makes a distinction between four types of English demonstratives for semantic and syntactic reasons: this/that as pro-forms, as "reduced" NPs, as demonstrative adjectives and determinative-that in terms of the presence or absence of their head nouns and the different nature as pro-forms and explores the semantic and or/syntactic properties of the demonstratives.

Pro-forms:

(1) Coming out the base of the brain like a stalk is the brain stem. This is the swollen top of the spinal cord, ... (McCarthy 1994)

"Reduced" NPs:

(2) There are a number of cases like this $\varnothing$ where Rule 2 does not apply, ... (Dixon, 1977)

Demonstrative adjectives:

(3) We'll refer to this D-structure marking as predicate analysis. If you do this predicate analysis whenever you draw a D-structure tree, you should find it much easier ... (Jacobs, 1995)

Determinative-that

(4) As we shall see in the next chapter, this definition is similar to that of the pathbreaking Russian narratologist Vladimir Propp (Toolan, 1988) (that = the definition = "the one")

Kim's classification of types of demonstratives provides a sound foundation for this paper to describe the distribution of demonstratives. This paper also classifies different type of antecedents of demonstratives. Botley and McEnery (2001) identify three antecedent types that are defined by the syntactic structure of that antecedent-namely, "nominal", "clausal" and "adjectival", which are realized as noun phrases, clauses, or adjectival phrases respectively. Fraurud (1992) defines everything that is not an NP, such as VPs, clauses, sentences, or stretches of texts as a non-nominal antecedent. Following Botley and McEnery (2001) and Fraurud (1992), I classify antecedents of anaphoric demonstratives into two types: nominal antecedents (which are realized as noun phrases) and non-nominal antecedents (which are realized as everything that is not an NP, such as VPs, clauses, sentences, or stretches of texts).

Nominal antecedent:

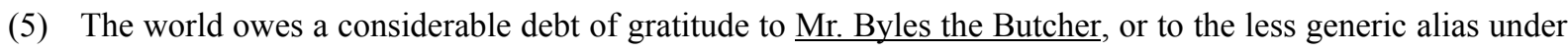
which this indispensable tradesman supplied the needs of the Stevenson family in Bournemouth in 1885 . (Botley \& McEnery, 2001)

Non-nominal antecedent:

(6) Novelist Wright Morris says he always is working on a book "because this is the way I breathe". (Botley \& McEnery, 2001)

What's more, it is also regarded as a demonstrative reference in this paper. This opinion derives from Halliday (1985) Strauss (1993). Halliday (1985) includes pronominal it as a member of the system of demonstrative reference, and Strauss (1993) also incorporates it into her framework in addition to this and that.

Base on the classification of demonstratives and antecedents mentioned above, this paper exams the interaction between the two types of demonstrative antecedents: nominal and non-nominal antecedents and four types of demonstratives: this/that/it as pro-forms, this/that as "reduced" NPs, this/that as demonstrative adjectives and determinative-that. The distribution of demonstratives with direct recoverable antecedents in English academic discourse is described from the perspective of interaction between anaphoric demonstratives and their antecedents. The purpose is to explore the distribution and specific properties of anaphoric demonstratives with directly recoverable antecedents in English academic discourse, assuming that the distribution of demonstratives in academic discourse is affected by the features of academic discourse and writer's perception of events in temporal order.

\section{Data}

The data used for this paper is taken from the academic section of the online corpus COCA (http://corpus.byu.edu/coca/). To be specific, the data are taken from the academic articles written in 2012, which belong to the "communication" part of the academic section of COCA.

All tokens of demonstrative reference of this, that, it from the above database of 50, 000 words were counted and classified according to the types of demonstratives (pro-forms, "reduced" NPs, demonstrative adjectives and determinative-that) and their antecedents (nominal and non-nominal antecedents). We first searched 
automatically all tokens of this/that/it in the mentioned database and find 231 tokens of this, 452 tokens of that and 213 tokens of $i t$. Because the interest of this paper is only about anaphoric demonstratives with directly recoverable antecedent, the author then counts manually all tokens of this/that/it with recoverable antecedents and classifies them according to the types of demonstratives and their antecedents. In order to make sure that all anaphoric demonstratives with directly recoverable antecedents are counted and classified correctly, the author asks two doctoral students and one master student who major in English linguistics to help. In all 359 tokens of this, that and it with directly recoverable antecedents are found and classified according to the types of demonstratives and antecedents. Table 1 shows the specific number and classification of these anaphoric demonstratives.

Table 1. Total tokens of anaphoric this, that and it

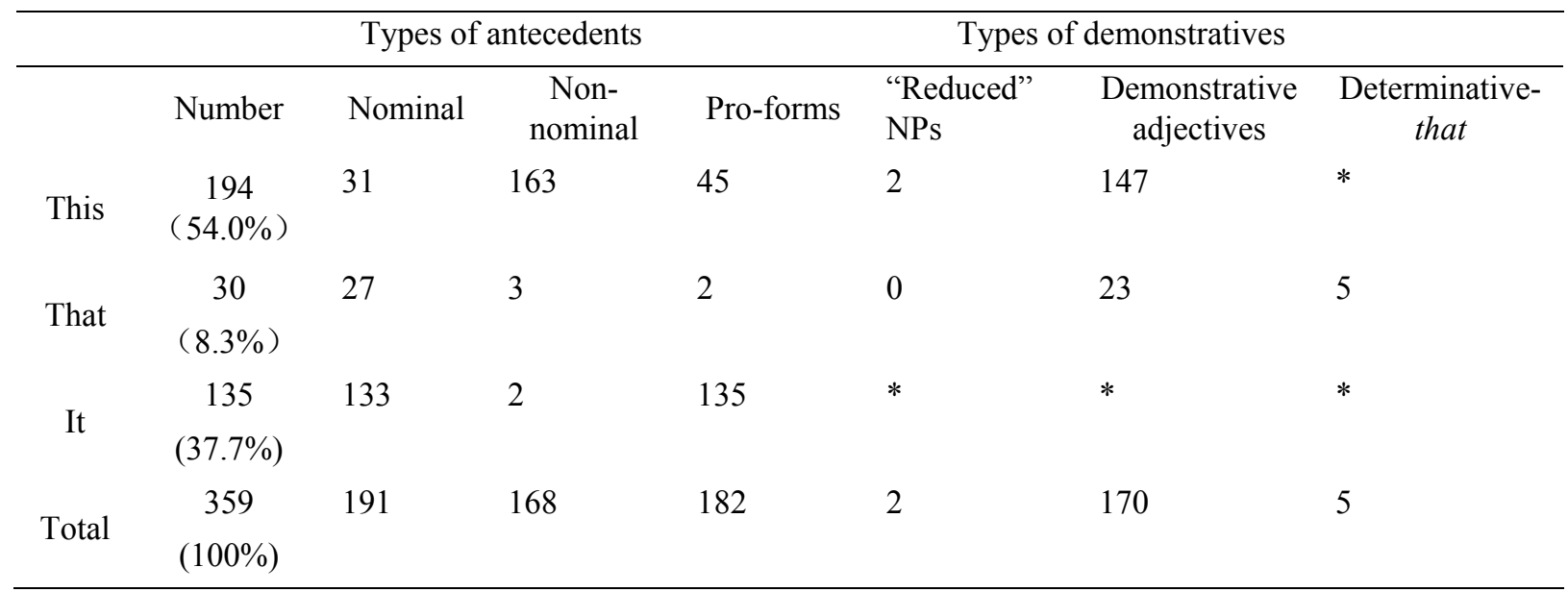

\section{Results and Discussion}

\subsection{General Analysis}

\subsubsection{Frequency of Demonstratives}

In our data, this accounts for more than half (54.0\%) of the total demonstratives, with it and that comprising the rest $(i t=37.7 \%$, that $=8.3 \%$ ). This matches other findings about frequency of demonstratives in written discourse. Nishimura (1996) discovers that this accounts for $83.4 \%$ of the total academic written discourse. Kirsner (1979) finds that the overall frequency of Dutch demonstrative determiner deze (deze=this) is higher in writing (56\%) than in speech.

The main reason for the frequency order of this $>$ it $>$ that $(>$ : more frequent) in academic discourse is due to the different functions of this/that $/$ it to mark topics. These functions correlate with features or purposes of academic discourse.

This often establishes its referent as the beginning of a discourse segment. It can mark the referent as the beginning of a new topic by giving an additional specification of the lexical content to its antecedent. What's more, this (especially this + adjective + noun) has a kind of evaluative function by providing an additional, more specific description of the writer's attitude or evaluation towards the referent and this allows "the writer to convey judgments and situate her/his positions in relation to knowledge and truth claims" (Diani, 2008, p. 32).

Bartholomae (1986) says that academic discourse is peculiar ways of knowing, selecting, evaluating, reporting, concluding, and arguing that define the discourse of our community. So the functions of this of giving an additional specification of the lexical content to its antecedent and of providing an additional, more specific description of the writer's attitude or evaluation towards the referent are in line with Bartholomae's statement about academic discourse.

Examples from the data:

(7) The code for the game with a Dr. Racket plug-in for syntax coloring is available online. You will find links in the accompanying sidebar. This plug-in colors the program according to the game language s syntax instead of Racket s default rules, highlighting lexical syntax errors in red. 
(8) A report released by ACM's Education Policy Committee (EPC) and Computer Science Teachers Association (CSTA), found that approximately two-thirds of the U.S. have few computer science education standards for secondary school education. In addition, most states treat high school computer science courses as simply an elective and not part of a student's core education. This landmark report addressed the vital need to build a strong K-12 computer science education program in schools throughout the U.S. that today largely does not exist.

The writer of an academic article also tends to "extract" non-nominal antecedents as propositions that function similarly as nouns. After "extracting" the non-nominal antecedents as propositions, the writer will "package" these propositions into pro-forms or the forms of demonstratives + nouns. These pro-forms and demonstratives + nouns then serve as markers of new topics and introduce new information about the "extracted" propositions. The following sentence shows this situation:

(9) Programmers may even be encouraged to think about a problem in terms of a language that would better support the task. This approach is sometimes called language-oriented programming.

It confirms the respective referent as the ongoing discourse topic or serves as the continuity of a topic. This function of $i t$ creates parallel constructions between antecedent-containing sentences and $i t$-containing sentences. In this way, more accurate and specific information revolving around the referent is introduced in a parallel and accumulative way. This function of it satisfies the requirement of accuracy and precision of academic discourse. Example:

(10) His choice of style was made for two reasons. First, it is a simple style that is familiar to most artists and yet expressive enough to depict shape. Second, it matches the style generated by several NPR rendering algorithms recently proposed in the CG literature.

That is a marker to end or shift a topic and it is often employed by the writer to conclude what has been discussed. Since it is only a shifting or ending marker, the demonstrative reference that does not add any information to the referent. This explains the infrequency of that in academic discourse. Example:

(11) This additional overhead is marginal and should be within the CA's capacity. Even if that capacity is exhausted, additional servers can scale the service and solve the capacity problem in a centralized manner.

\subsubsection{Types of Antecedents}

Among 359 instances of antecedents, 191 (53.2\%) antecedents are nominal and 168 (46.8\%) antecedents are non-nominal. It seems that the distribution of nominal antecedents and non-nominal antecedents is almost the same. However when we come to the specific demonstratives, we find the difference. Among the 194 tokens of antecedents of this, $163(84.0 \%)$ antecedents are non-nominal (among these, most are clausal) and only 31 $(16.0 \%)$ are nominal. Considering the 30 tokens of antecedents of that, $27(90.0 \%)$ tokens are nominal and 3 $(10.0 \%)$ tokens are non-nominal. With respect to the 135 instances of $i t, 133(98.5 \%)$ tokens are nominal and only 2 examples of non-nominal antecedents. So the general trend of types of antecedents we find in our study is the following: Both nominal and non-nominal elements can serve for antecedents of demonstratives. For demonstrative this, most of its antecedents are non-nominal. But for $i t$ and that, most antecedents are nominal.

Webber (1979) and Kamp and Reyle (1993) once defined nominal antecedents coming into a discourse mode as discourse entities. Grosz and Sidner (1986) regarded non-nominal antecedents as discourse segments. However they only discussed the distinction between demonstratives and other referring phrases with regarding to different antecedents from a cognitive perspective. No distinction was made between different terms in demonstrative system. But the distinction between different demonstratives with different antecedents is what we consider in the present study and this distinction helps us to discuss the interaction between anaphoric demonstratives and their antecedents.

\subsubsection{Types of Demonstratives}

In the data examined, cases of pro-forms and demonstrative adjectives are more highly frequent than the cases of "reduced" NPs and determinative-that. This finding is reflected in the frequency distributions obtained for similar phenomenon by Botley and McEnery (2001) in three different corpora. However there are variations between the three demonstratives. Within the cases of this, demonstrative adjectives (75.8\%) display a higher percentage than pro-forms $(23.2 \%)$. It is also worth noting that when using as an adjective, this often combines with other elements to modify its head noun and provides new and more information about its antecedent. About the cases of that, cases of adjectives (76.7\%) are more frequent than cases of pro-forms $(6.7 \%)$. This trend is similar to the distribution of cases of this. Even though, a difference should be noticed. Being a demonstrative adjective, that seldom combines with other elements to modify a noun. 
The usage of it seems simple because it cannot connect with nouns and can only be used as a pro-form. Other two categories-“reduced" NPs and determinative-that - noticed by Kim (2006) are rather rare in the academic articles we examined.

Why do demonstratives distribute in this way? In the author's opinion, this distribution has close relationship with the characters of academic discourse. Elbow (1991) provides four characters of academic discourse. Among these four characters, two are related with our discussion: (a) a version of reality that values explicitness and straightforward organization; (b) an element of display of a tendency to show off.

Demonstratives as pro-forms and demonstrative adjectives can not only refer back to their antecedents but also can "package" previously-mentioned complex information into a nominal phrase. This pattern of "information package" helps the writer include large quantity of information in her/his article and elaborate the information in an explicit and "straight forward" structure.

Francis (1994) defines demonstrative adjectives with non-nominal antecedents as "retrospective labels" and Kim (2006) mentions them as the labeling or rephrasing this/that $+N$. Their function is to summarize or interpret the previous sentences (Swales \& Feak, 2000) and to give the reader more explicit cues about the interpretation of the text (Mauranen, 1993). Furthermore, demonstrative adjectives can combine with other modifiers to polish nouns and this function helps the writer to "squeeze" more information in a short phrase and meet the feature of being an element of display or a tendency to show off.

So in academic discourse, demonstrative adjectives and pro-forms contribute to the efficient delivery of information in a neat and clear way. And in order to catch the characters of academic discourse, a writer will first choose demonstrative adjectives and then pro-forms.

\subsubsection{Relations between Demonstratives and Their Antecedents}

Different semantic relations hold between demonstratives and their antecedents can de found in academic discourse. In our data, three main relations are recognized: direct coreference, indirect coreference and labeling or rephrasing relations.

Relationship of direct corefence:

This relationship exists only between demonstrative adjectives and their nominal antecedents. It means that a demonstrative corefers with its antecedent. Syntactically, the demonstrative and its nominal antecedent have the same nominal head.

(12) The same VM image can be run on computers with different I/O devices and configurations, with the I/O virtualization layer providing the necessary conversion. ... This $\mathbf{I} / \mathbf{O}$ virtualization layer may also change mappings to physical devices, even when the VM itself does not move.

Relationship of indirect coreference:

Relationship of indirect coreference holds between demonstrative it and their nominal antecedents or demonstrative adjectives and their nominal antecedents. It means that a demonstrative corefers with its antecedent by using different syntactic forms. Or if the semantic relation holding between demonstrative and its nominal antecedent is hyperhymy or synonymy, it is also a kind of indirect coreference.

(13) While virtualization offers many benefits, it also introduces significant challenges.

(14) The CCN content model build up a network of many secured relationships: Each piece of data is bound to its name and publisher s key; names are implicitly bound to other names by the naming hierarchy and application-level naming conventions; publishers are bound to other publishers by the key certification graph. As a consumer accumulates content, this web of trusted relationships can be used to automatically infer trust in entire collections of content. (Synonymy)

Labeling or rephrasing relations (Francis, 1994; Kim, 2006)

Labeling or rephrasing relations mainly refer to the relationship between demonstratives and their non-nominal antecedents. The function of these demonstratives is "to encapsulate or package a stretch of discourse" (Francis, 1994, p. 85) or "rephrase the antecedents so that the writer may evade its simple repetition and need the further elaboration" (Kim, 2006, p. 202).

(15) ACM's Education Board and ACM India are joining forces to spearhead a vital initiative to determine how best to improve the quality of undergraduate computing education in India. This cooperative effort also includes key educators in India and is designed to support and strengthen computing education throughout the country. 
Table 2. Relations between demonstratives and their antecedents

\begin{tabular}{|c|c|c|c|c|c|c|c|c|c|c|c|c|}
\hline & \multicolumn{3}{|c|}{ Pro-forms } & \multicolumn{3}{|c|}{ "Reduced" NPs } & \multicolumn{3}{|c|}{ Demonstrative adjectives } & \multicolumn{3}{|c|}{ Determinative-that } \\
\hline & this & that & it & this & that & $i t^{*}$ & this & that & $i t^{*}$ & This* & that & $i t^{*}$ \\
\hline Nominal & $*$ & $*$ & IC & $\mathrm{IC}$ & $*$ & & $\mathrm{DC} / \mathrm{IC}$ & $\mathrm{DC}$ & & & $\mathrm{IC}$ & \\
\hline Non-nominal & $\mathrm{L} / \mathrm{R}$ & $\mathrm{L} / \mathrm{R}$ & $\mathrm{L} / \mathrm{R}$ & * & * & & $\mathrm{L} / \mathrm{R}$ & $\mathrm{L} / \mathrm{R}$ & & & * & \\
\hline
\end{tabular}

(Note: DC: direct coreference; IC: indirect coreference; L: labelingor rephrasing)

Semantic relations established between demonstratives and their antecedents lead readers to follow the writer's flow of thought and to understand the writer's organization of information. Especially the labeling or rephrasing relations function as signals for stages of an argument, developed in and through the discourse itself as the writer presents and assesses his or her proposition (Francis, 1994).

\subsection{Specific Analysis}

\subsubsection{Analysis of This}

It is clear that most antecedents of this (84.0\%) are non-nominal in our data. To refer back to these non-nominal antecedents, writers tend to choose this as demonstrative adjectives or as pro-forms: among 161 tokens of non-nominal antecedents, there are $116(72.0 \%)$ tokens of this as demonstrative adjectives and $45(28.0 \%)$ tokes of this as pro-forms. No tokens of this as "reduced" NPs are chosen to refer to non-nominal antecedents. The tokens of this with different antecedents re shown in table 3 :

Table 3. This (Combination of demonstratives and their antecedents)

\begin{tabular}{llll}
\hline & Nominal & Non-nominal & Total \\
\hline Pro-forms & 0 & 45 & $45(23.2 \%)$ \\
"Reduced" NPs & 2 & 0 & $2 \quad(1.0 \%)$ \\
Demonstrative adjectives & 31 & 116 & $147 \quad(75.8 \%)$ \\
Total & $33(17.0 \%)$ & $161(83.0 \%)$ & $194 \quad(100 \%)$ \\
\hline
\end{tabular}

Two different types of situations can be noticed in the cases of this as demonstrative adjectives with non-nominal antecedents. The first type of situation is a "repetition" relationship holds between the head noun of this and its antecedent: one adjective or verb containing in the antecedent is "nominalized" as the head noun of this. The second type of situation is a "summary" relationship holds between the head noun of this and its antecedent. The latter situation displays a higher frequency than the former one because the latter situation can provide more information. Sentence (16) and sentence (17) from the data show the "repetition" relationship and the "summary" relationship holds between the head noun of this and its antecedent respectively:

(16) The DL, now available $i_{i}$ at 2,650 institutions in 64 countries, boasts an estimated 1.5 million users worldwide. The result of this availability $\mathrm{y}_{\mathrm{i}}$ led to more than 16 million full-text downloads during FY11.

(17) Programmers may even be encouraged to think about a problem in terms of a language that would better support the task. This approach is sometimes called language-oriented programming.

In our data, we also find that the head nous following this to "summarize" the non-nominal antecedents can be classified into several types: idea/point/notion; approach/module/mode; example/case/sample; feature/property; event; situation ... All these nouns share a feature of being abstract nouns and they indicate that the content conveyed by their antecedents are viewpoints, methods, facts, events, situations etc.

Another point attracts our attention is that when this is used as a pro-form, it is often used as a subject and the verbs following it are only a few types: be/mean/show/explain/express, leave/lead to, match... These verbs are appropriate words to discuss abstract propositions. Verbs such as be/mean/show/explain/express are used to explain propositions, leave/lead to are used to discuss about the effects or results of theories or arguments and match is used to compare two propositions. In an academic article, if we want to talk about an argument, we need to explain it, elaborate its influence and sometimes compare it with other theories to highlight its similarity to or differences with other theories. The tendency of verbs after this actually reflects one function of academic 
discourse to synthesize, evaluate or judge validity of arguments (Adamson, 1993).

Considering nominal antecedents, one feature is that most nominal antecedents of this are indefinite NPs with long series of modifiers before or after them. Still with respective to nominal antecedents, one distinction can be made between modifier-demonstratives with head nouns that provide new information about their antecedents and those that simply corefer with their antecedents, without any new information being provided. (Botley \& McEnery, 2001). Actually this is a distinction between "this + noun" and "this + adjective + noun". In addition, this distinction also exists between demonstrative adjectives this and that. In our data, we find $19(61.3 \%)$ tokens of "this + adjective + noun" among 31 cases of this as demonstrative adjectives but no tokens of "that + adjective + noun". Making nominal antecedents and head nouns of this contain other modifiers, the writer does her/his utmost to deliver more information. See sentence (18):

(18) A report released by ACM s Education Policy Committee (EPC) and Computer Science Teachers Association (CSTA), ... This landmark report addressed the vital need to build a strong K-12 computer science education program in schools throughout the U.S. that today largely does not exist.

Table 4. Specific features of this and its antecedents

\begin{tabular}{|c|c|c|c|c|}
\hline & Pro-forms & $\begin{array}{l}\text { "Reduced" } \\
\text { NPs }\end{array}$ & Demonstrative adjectives & \\
\hline Nominal & & This $+\varnothing$ & $\begin{array}{l}\text { This+(adjective })+ \text { noun } \\
\text { This }+(\text { adjective })+\text { noun }\end{array}$ & $\begin{array}{c}\text { concrete/abstract noun } \\
\text { "repetition" }\end{array}$ \\
\hline $\begin{array}{c}\text { Non- } \\
\text { nonimal }\end{array}$ & $\begin{array}{c}\text { This }+ \text { verb } \\
\text { be/mean/show/explain/express } \\
\text { leave/lead to } \\
\text { match }\end{array}$ & & $\begin{array}{c}\text { This }+ \text { (adjective)+noun } \\
\text { idea/point/notion } \\
\text { approach/module/mode } \\
\text { example/case/sample } \\
\text { event/situation/property }\end{array}$ & $\begin{array}{l}\text { abstract noun } \\
\text { "summary" }\end{array}$ \\
\hline
\end{tabular}

To summarize, the author finds a tendency about demonstrative this with different antecedents in academic discourse: the most common antecedent type is non-nominal type. The frequency order of types of demonstrative this is: demonstrative adjectives > pro-forms > "reduced" NPs. And when this is used as a demonstrative adjective, the nouns following this tend to be abstract. Another features about demonstrative this is that it often combines with other adjectives to modify its head noun.

\subsubsection{Analysis of That}

In academic discourse, demonstrative that is a peripheral choice. Only 30 tokens (8.6\%) of that are found among 359 tokens of demonstratives. This is different from the situation in spoken discourse: $30 \%$ tokens of that were found in Strauss's study on this/that/it in spontaneous oral discourse. To a certain degree, this shows the influence of genres on the choice of demonstratives.

Even distributing in a very low percentage, demonstratives that and their antecedents show some tendency: most of the antecedents (90.0\%) are nominal and more than three quarters $(76.7 \%)$ of the cases of that are used as demonstrative adjectives. What's more, 5 cases of determinative-that are discovered in our data.

In the cases of that with nominal antecedents, 20 token (74.1\%) are referred back by "that + noun" and 5 tokens $(18.5 \%)$ are referred back by determinative-that. One salient property about "that + noun" is that we don't find any modifiers before the head nouns of that, which is different from the cases of "this + noun". What's more, the lexical head noun that co-occurs with that is, in most cases, a repetition of the nominal antecedent. Just as what we mentioned before, that is a "shifting" or "ending" topic marker and it is only used to encapsulate a proposition that is then commented on in passing in a paragraph-final stretch of text, so it is not necessary for "that + noun" to add new information to the antecedent.

(19) All these projects involved a useful mix of physical and simulated elements, but that mix was fixed.

Kim (2006) mentions that determinative-that is a kind of "type-identifiable" substitute pro-form and it often occurs in comparative, equative or coordinate contexts. And all the 5 examples of determinative-that discovered 
in our data are used to identify the type recognized by their antecedents and all of them are used in comparative contexts. These examples prove the correctness of Kim's statement about determinative-that.

(20) Despite this extra richness in CCN names, their transport function in Interties exactly the same as that of sequence numbers in TCP ACKs: specifying the next Data the recipient requires.

(21) As measured by voice quality, the performance of our secure VOCCN prototype was equivalent to that of stock linphone.

The choice of determinative-that in academic discourse helps the writer to avoid redundancy and achieve the effect of being concise and economic.

The low frequency of non-nominal antecedents of that is obvious in our data and only 3 tokens are discovered. This conforms to what others have found (Botley \& McEnery, 2001; Oh, 2001).

Table 5 shows the distribution of that with different antecedents:

Table 5. That (Combination of demonstratives and their antecedents)

\begin{tabular}{llll}
\hline & Nominal & Non-nominal & Total \\
\hline Pro-forms & 0 & 2 & $2(6.7 \%)$ \\
"Reduced" NPs & 0 & 0 & $0(0.0 \%)$ \\
Demonstrative adjectives & 20 & 3 & $23(76.7 \%)$ \\
Determinative-that & 5 & 0 & $5(16.6 \%)$ \\
Total & $25(83.3 \%)$ & $5(16.7 \%)$ & $30(100 \%)$ \\
\hline
\end{tabular}

To sum up, most antecedents of that in academic discourse are nominal and a few are non-nominal. As far as cases of demonstrative that are concerned, demonstrative adjectives are more highly frequent than other types. In addition, head nouns of that are often repetitions of their nominal antecedents and no modifiers existing between head nouns and that. And "type-identifiable" determinative-that is also exploited by the writer to achieve concise and economic effect in discourse writing.

\subsubsection{Analysis of It}

In our data, the most significant frequency (98.5\%) is for $i t$ with nominal antecedents. One remarkable feature of nominal antecedents of $i t$ is that they often occur in the order of a $+\mathrm{NP}$ (the theme or rheme of a clause) $\rightarrow$ the + NP (mostly the theme of the next clause) $\rightarrow i t$ (the theme of the following clause). Another feature of $i t$ is that it can be used to create parallel constrictions and to mark continuity of a topic. This illustrates that demonstrative it and its antecedents play a crucial part in creating cohesion of academic articles.

It is reasonable to conclude that we use it to refer back to entities that have been just written about. It does not give any particular emphasis but serves as a marker of topic continuity. See sentence (22) (23) and table 6:

(22) The property of the procedure clause in the declaration of typed makes a typed instance act as a function (for reasons explained later). The function takes one argument in addition to the implicit self-argument, but it ignores the argument and returns the typed instances id.

(23) His choice of style was made for two reasons. First, it is a simple style that is familiar to most artists and yet expressive enough to depict shape. Second, it matches the style generated by several NPR rendering algorithms recently proposed in the CG literature.

Table 6. It (Types of antecedents)

\begin{tabular}{lll}
\hline Types of antecedents & Number & Percentage \\
\hline Nominal & 133 & $98.5 \%$ \\
Non-nominal & 2 & $1.5 \%$ \\
Total & 135 & $100 \%$ \\
\hline
\end{tabular}




\subsection{Underlying Motivations for the Interaction between Demonstratives and Their Antecedents}

The underlying motivation for the interaction between demonstratives and their antecedents is the writer's perception of events in temporal order. Mellor (1985) mentions it must be the actual temporal order of the perceptions of two events which allows us to represent the temporal order of the event perceived. Though his statement is used to explain the representation of events, we can borrow this statement to explain why antecedents can interact with the choice of demonstratives.

Antecedents are first represented in a sentence, so their features of course will influence the choice of the later-appeared demonstratives. For example, if the antecedents are non-nominal, this non-nominal representation will force the writer to make an option between this/that/it as another representation.

\section{Conclusion}

Different from the proximity approach and the focus approach, this paper discusses anaphoric demonstratives and their antecedents by examining their specific semantic, syntactic and discourse properties in context. Interaction between demonstratives and features of academic discourse is also examined.

In our data, the general frequency of demonstratives is this $>$ it $>$ that. The main reason underlying this order is that this establishes its referent as the beginning of a discourse segment; it confirms the respective referent as the ongoing discourse topic and that is a marker to end or shift a topic. About antecedent types, the frequency of nominal and non-nominal antecedents is almost the same. However when we consider specific demonstratives, we find that most antecedents of this are non-nominal and most antecedents of $i t$ and that are nominal.

In the data examined, cases of demonstrative adjectives and pro-forms are more highly frequent than the cases of "reduced" NPs and determinative-that. When used as demonstrative adjectives, this often combines with other modifiers but that seldom combines with other modifiers to modify a noun. Three main relations can be recognized: direct coreference, indirect coreference and labeling or rephrasing relations. These relations help readers to follow the writer's stages of an argument and the way that she/he presents and assesses his or her proposition.

Considering demonstrative this, the most common antecedent type is non-nominal type. The frequency order of types of demonstratives is: demonstrative adjectives > pro-forms > "reduced" NPs. When this is used as demonstrative adjectives, the nouns following this tend to be abstract. When this functions as pro-forms, verbs following this belong to certain types of "explanation" "comparison" "effect". Another feature about demonstrative this is that it often combines with adjectives to modify its head noun.

Demonstrative that is a peripheral type. Most antecedents of that are nominal and more than three quarters of the cases of that are used as demonstrative adjectives. Some cases of determinative-that are discovered. Functioning as a demonstrative adjective, that doesn't combine with other modifiers and the lexical head noun of that is only a repetition of the antecedent. Determinative-that is a kind of "type-identifiable" substitute pro-form and it can avoid redundancy.

The most significant frequency is for it with nominal antecedents. One remarkable feature of nominal antecedents of $i t$ is that they often occur in an order of $a+N P$ (the theme or rheme of a clause) $\rightarrow$ the $+N P$ (mostly the theme of the next clause) $\rightarrow i t$ (the theme of the following clause). Another feature of $i t$ is that it can be used to create parallel constrictions and to mark the continuity of a topic. This illustrates that demonstrative $i t$ and its antecedents play crucial parts in cohesion of academic articles.

The findings about anaphoric demonstratives and their antecedents in this paper will help us to consider the choice of demonstratives made by writers from a very specific and distinct way and the findings can also help language learners to choose appropriate demonstratives in their academic writing.

However, due to the limited amount of data, larger amount of data are needed to verify what we find in this paper. And in order to present a more general picture of demonstratives from a semantic, syntactic and discourse perspective, other genres of data and other parameters should be involved. This is one of the orientations for our further study.

\section{References}

Admanson, H. D. (1993). Academic Competence: Theory and Classroom Practice: Preparing ESL Students for Content Course. New York: Longman.

Banholomae, D. (1986). Inventing the university. Journal of Basic Writing, 5, 4-23.

Botley, S., \& McEnery, T. (2001). Demonstratives in English-A corpus-based study. Journal of English 
Linguistics, 1, 7-33. http://dx.doi.org/10.1177/00754240122005170

Diani, G. (2008). Emphasizers in spoken and written academic discourse. In U. Römer, \& R. Schulze (Eds.), Patterns, Meaningful Units and Specialized Discourse. Special Issue of International Journal of Corpus Linguistics, 13(3), 296-321.

Elbow, P. (1991). Reflections on academic discourse: How it relates to freshmen and colleges. College English, 53, 135-155. http://dx.doi.org/10.2307/378193

Fillmore, C. J. (1997). Lectures on Deixis. Standford, California: CSLI Publications.

Francis, G. (1994). Labelling discourse: An aspect of nominal-group lexical cohesion. In C. Malcolm (Ed.), Advances in Written Text Analysis (pp. 83-101). London \& New York: Routledge.

Fraurud, K. (1992). Processing noun phrases in natural discourse (Unpublished doctoral dissertation). Stockholm University.

Grosz, B., \& Sidner, C. (1986). Attention, intention and the structure of discourse. Computational Linguistics, 3, 175-204.

Halliday, M. A. K. (1985). An introduction to functional grammar. London: Edward Arnold.

Halliday, M. A. K., \& Hasan, R. (1976). Cohesion in English. London: Longman.

Huddleston, R. (1984). Introduction to the Grammar of English. Cambridge: Cambridge University Press. http://dx.doi.org/10.1017/CBO9781139165785

Kamp, H., \& Reyle, U. (1993). From Discourse to Logic. Dordrecht, the Netherlands: Kluwer Academic Publishers. http://dx.doi.org/10.1007/978-94-017-1616-1

Kaplan, J. P. (1989). English Grammar: Principles and Facts. Englewood Cliffs, NJ: Prentice Hall.

Kim, D. S. (2000). A Comparison of This and That in Discourse. A paper read at the 2000 spring conference, the Association of English Language and Literature in Korea.

Kim, D. S. (2006). Distinctive Properties of English Demonstratives in Written Discourse. 현대영미어문학, 11, 189-211.

Kirsner, R. S. (1979). Deixis in discourse: An exploratory quantitative study of the modern Dutch demonstrativeadjectives. In T. Givon (Ed.), Syntax and Semantics: Vol. 12. Discourse and Syntax (pp. 355-375). New York: Academic Press.

Lakoff, R. T. (1974). Remarks on This and That. In Papers from the $10^{\text {th }}$ Regional Meeting of the Chicago Linguistics Society (pp. 345-356). Chicago: Chicago Linguistics Society.

Levinson, S. C. (1983). Pragmatics. Cambridge: Cambridge University Press.

Linde, C. (1979). Focus of Attention and the Choice of Pronouns in Discourse. In T. Givon (Eds.), Syntax and Semantics: Vol. 12. Discourse and Syntax (pp. 337-354). New York, NY: Academic Press.

Mauranen, A. (1993). Cultural Differences in Academic Rhetoric: A Text Linguistic Study. Frankfurt am Main: Peter Lang.

Mellor, D. H. (1985). Real Time. Cambridge: Cambridge University Press.

Nishimura, C. (1996). Demonstratives in Academic Written English Discourse (Unpublished master's thesis). University of California.

Oh, S. Y. (2001). A focus-based study of English demonstrative reference-With special reference to the genre of written advertisements. Journal of English Linguistics, 2, 124-148. http://dx.doi.org/10.1177/00754240122005260

Quirk, R. S., Greenbaum, S., Leech, G. N., \& Svartvik, J. (1985). A Comprehensive Grammar of the English Language. London: Longman.

Ramsey, S. (1968). The English Language and English Grammar: A Historical Study. New York: Haskell House.

Sinder, C. L. (1983). Focusing in the comprehension of definite anaphora. In M. Brady, \& R. C. Berwick (Eds.), Computational Models of Discourse (pp. 267-330). Cambridge, MA: MIT Press.

Strauss, S. (1939b). Why 'this' and 'that' are not complete without 'it'. In CLS 29: Papers From the $29^{\text {th }}$ Regional Meeting of the Chicago Linguistics Society (pp. 403-417). Chicago: Chicago Linguistics Society.

Swales, J. M., \& Christine, B. F. (2000). English in Today's Research World: A Writing Guide. Ann Arbor, 
Michigan: The University of Michigan Press.

Webber, B. A. (1959). Formal Approach to Discourse Anaphora. New York, NY: Macmillan Co.

Wilfley, D. E. (1989). Interpersonal analyses of bulimia (Unpublished doctoral dissertation). University of Missouri.

\section{Copyrights}

Copyright for this article is retained by the author(s), with first publication rights granted to the journal.

This is an open-access article distributed under the terms and conditions of the Creative Commons Attribution license (http://creativecommons.org/licenses/by/3.0/). 